\title{
A produção de materiais geoeducativos na proposta do Geoparque Quarta Colônia, RS
}

\section{The production of geoeductive materials in the proposal of the Fourth Colony Geopark, RS}

Adriano Figueiró, Docente do Departamento de Geociências, Universidade Federal de Santa Maria, Brasil, adriano.figueiro@ufsm.br

(1) https://orcid.org/ 0000-0002-4988-771X

Vinicius Motta, Graduandos de Geografia da Universidade Federal de Santa Maria, Brasil, viniciusmottaufsm@gmail.com

(1) https://orcid.org/0000-0002-1509-1860

Thainara Brunhauser, Graduandos de Geografia da Universidade Federal de Santa Maria, Brasil, tbrunhauser@yahoo.com

(1) https://orcid.org/0000-0003-4641-9707

Harrison Ventura, Graduandos de Geografia da Universidade Federal de Santa Maria, Brasil, harissonventura@gmail.com

(1) https://orcid.org/0000-0003-2455-6700

Dilson Cechin, Docente do Departamento de Arquitetura da Universidade Federal de Santa Maria e doutorando do PPGGEO-UFSM, Brasil, dilsonnc@gmail.com

(1) https://orcid.org/0000-0002-7976-7786

Resumo: Na região central do Rio Grande do Sul (Brasil), nove municípios com grande relevância no patrimônio geológico-geomorfológico, paleontológico e histórico-cultural representam o território de uma das propostas de geoparque atualmente em construção. A riqueza patrimonial desse território se expressa em fósseis triássicos de grande raridade, feições e processos geomorfológicos típicos de ambientes de transição entre planaltos escarpados e extensas áreas de deposição aluvial, grande biodiversidade e testemunhos culturais preservados, que remontam à imigração italiana e alemã ocorrida neste território na segunda metade do século XIX. Diversos estudos apontam sobre a importância de estratégias pedagógicas que possam atuar neste contexto. Assim, materiais geoeducativos servem como ferramentas de disseminação do conhecimento científico, porém para a construção destes instrumentos é necessária uma abordagem que contemple o contexto dos sujeitos envolvidos e do território em questão. Alguns materiais educativos já estão sendo desenvolvidos, como um jogo de Role Playing Game (RPG), um caderno didático do geoparque quarta colônia e uma maquete em grande formato do território, traduzindo para uma linguagem escolar a riqueza geopatrimonial do território. A elaboração destes materiais resulta em ferramentas estratégicas de conscientização e valorização do patrimônio e no despertar do interesse do uso dos geossítios como atração geoturística.

Palavras-chave: Geoeducação; Geoparque Quarta Colônia; Instrumentos pedagógicos; Geoconservação.

\begin{abstract}
In the central region of Rio Grande do Sul (Brazil), nine municipalities with great relevance in geological-geomorphological, paleontological and historical-cultural heritage represent the territory of one of the project of geopark currently under construction in the state. The heritage richness of this territory is expressed in very rare Triassic fossils, features and geomorphological processes typical of transitional environments between rugged plateaus and extensive areas of alluvial deposition, great biodiversity and preserved cultural heritage evidence dating back to italian and german immigration in this territory in the second half of the 19th century. Several studies point to the importance of pedagogical strategies that can act in this context, Thus, geo-educational materials serve as tools for the dissemination of scientific knowledge. However, the construction of these instruments requires an
\end{abstract}


approach that contemplates the context of the subjects involved and the territory in question. Some educational materials are already being developed, such as a Role Playing Game (RPG), a fourth colony geopark textbook and a large-scale model of the territory, translating the geopatrimonial richness of the territory into a school language. The elaboration of these materials results in strategic tools of awareness and appreciation of heritage and in the awakening of the interest of the use of geosites as a geotouristic attraction.

Keywords: Geoeducation; Fourth Colony Geopark; Pedagogical instruments; Geoconservation.

\section{Introdução}

Cada vez mais os modelos de turismo sustentável que se desenvolvem ao longo de diferentes paisagens do mundo buscam conciliar a proteção patrimonial com a exploração sustentável dos recursos, gerando desenvolvimento local, capaz de promover uma melhoria da condição de vida dos habitantes destas regiões.

Uma das estratégias mais bem-sucedidas neste sentido é a dos geoparques, estabelecidos por redes de cooperação continentais de territórios da Global Geoparks Network (GGN), certificados pela UNESCO. Os geoparques são territórios que compreendem um geopatrimônio único, e desenvolvem uma gestão que busca o desenvolvimento local e a geoconservação (Borba, 2011). Para Pereira (2010), geoparques podem ser entendidos como sistemas sustentáveis de gestão territorial que podem ser aplicados a territórios delimitados que englobem um conjunto de geossítios com relevância em termos científicos, estéticos, culturais, científicos e educativos.

De acordo com Borba (2011), o geoturismo é uma das atividades mais importantes realizadas num geoparque. O geoturismo busca, além da valorização e interpretação do geopatrimônio, um novo modelo de desenvolvimento para localidades que muitas vezes não se enquadram no padrão capitalista de produção de mercadorias, mas, ao mesmo tempo, possuem um geopatrimônio exuberante, uma cultura ímpar e uma história riquíssima. Esse é o caso do território da Quarta Colônia, onde se desenvolve este trabalho.

Em que pese a importância da riqueza patrimonial do território na implantação de um geoparque, Farsani et al. (2014) advertem que a existência de projetos educacionais é um fator-chave no conhecimento, gestão e preservação de geoparques como novo nicho turístico. Tais projetos definem um campo geoeducativo do conhecimento que, segundo os autores (op.cit.) não compreende apenas o ensino formal de geociências, mas também envolve o conhecimento de dados empíricos e experiências práticas sobre a preservação da Terra.

Portanto, a geoeducação não pode ser interpretada apenas como ensino de conceitos ligados às Ciências da Terra, mas a um conjunto de conhecimentos e saberes, escolares e não escolares, voltados a crianças, jovens e adultos, no sentido de prepara-los para interpretar e agir no seu território, em busca de melhores condições de vida e de manutenção do seu patrimônio coletivo. Precursora do uso do termo, a National Geographic Society descreve a geoeducação como a educação para um 
mundo interconectado (Figura 1). Também chamada de "Geo-alfabetização", este campo de conhecimento refere-se à "compreensão dos sistemas e interconexões da Terra de que todos precisamos para tomar boas decisões" (Edelson, 2012, p.1). Com isso, a geoeducação fornece as ferramentas que permitem às comunidades proteger o seu patrimônio natural e cultural, reduzindo os conflitos e melhorando a qualidade de vida nos seus territórios, mantendo a competitividade econômica por meio de um uso sustentável do território aliado ao fortalecimento do capital social. Tudo isso, segundo Edelson (2012) a partir de três componentes básicos: interações (como o mundo funciona), interconexões (como as pessoas e os territórios se ligam e se relacionam) e implicações (como interações e interconexões determinam os resultados das ações).

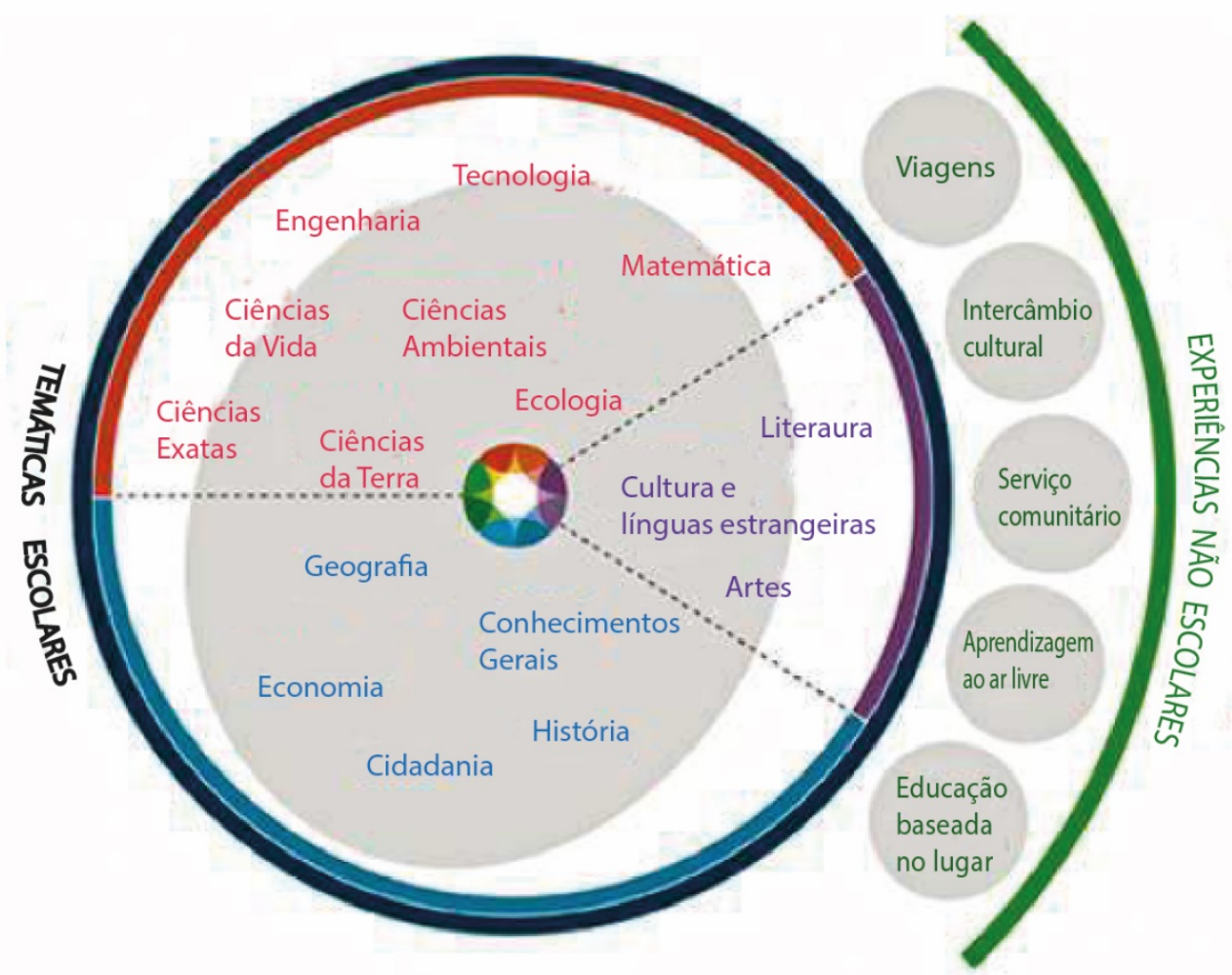

Figura 1: Esquema das principais áreas de conhecimento envolvidas no processo geoeducativo, envolvendo temáticas escolares e experiências não escolares da educação não formal e informal.

Fonte: NGS (sd).

Para Azman et al. (2011), o aprendizado escolar, ou mesmo extra-escolar, acerca dos mecanismos e dinâmicas da natureza e da cultura que formam o patrimônio do território, representa apenas a etapa inicial daquilo que os autores entendem como geoeducação (Figura 2), já que educar uma comunidade para compreender, divulgar e proteger o seu patrimônio, implica, necessariamente, fortalecer os eixos centrais que estruturam o capital social desta comunidade. Assim, questões como o compartilhamento de valores dentro da comunidade, o desenvolvimento de lideranças e responsabilidade, o empreendedorismo e a capacitação para o atendimento dos 
visitantes são, também, questões que estão diretamente relacionadas com a geoeducação lato sensu.

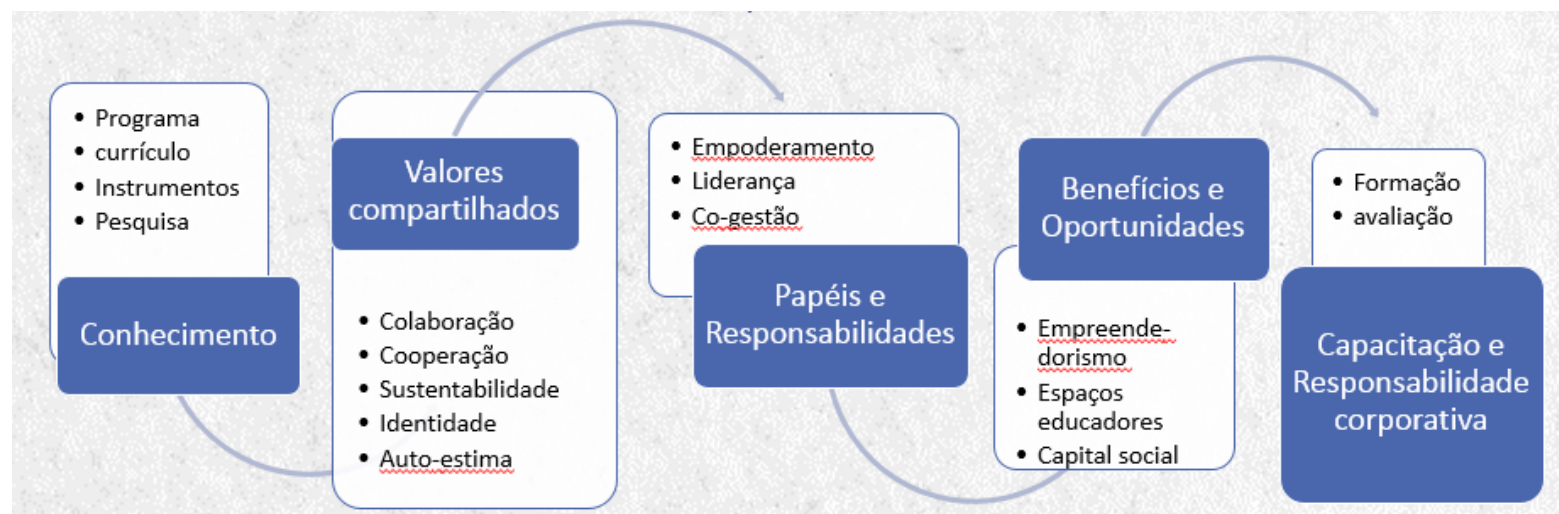

Figura 2: A compreensão do conhecimento envolvido na interpretação do patrimônio natural e cultural do território, representa o ponto inicial da geoeducação, a partir de onde toda a formação dos indivíduos se desenrola, envolvendo a aquisição de novos conhecimentos e a geração de atitudes necessárias ao desencadeamento dos processos de conservação e desenvolvimento local sustentável.

Fonte: Adaptado de Azman et al. (2011).

Ao subsidiar o processo interpretativo que acompanha a geoconservação, a qual, por sua vez, é condição essencial para a promoção e o geoturismo no território, a geoeducação se coloca como um dos pilares básicos de sustentação do Geoparque (Figura 3). Ao mesmo tempo em que estabelece as bases pedagógicas sobre as quais se constroem todos os processos interpretativos do território, a geoeducação também responde às novas demandas que vão sendo criadas a partir do geoturismo, em um processo contínuo de retroalimentação (Van Loon, 2008).

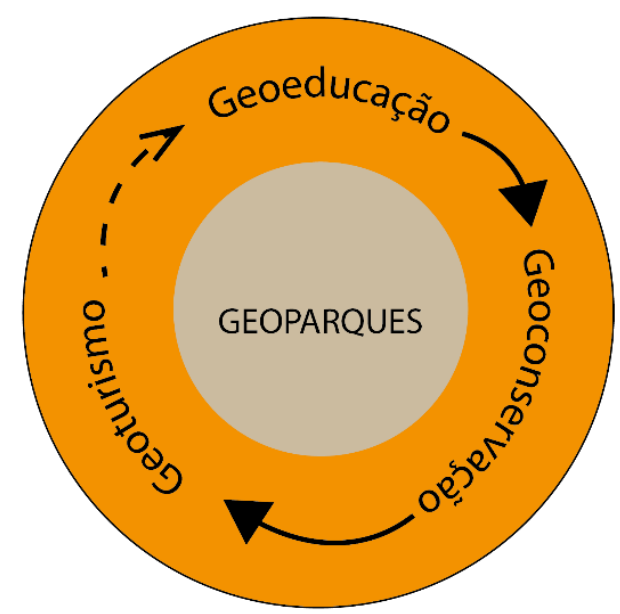

Figura 3: Esquema dos pilares que definem o uso sustentável do território nos Geoparques.

Fonte: Elaboração dos autores.

Esta retroalimentação entre o geoturismo e a geoeducação representa a permanente geração de demandas formativas de indivíduos em um geoparque para, num primeiro momento, atuarem nos museus, centros interpretativos e guiamento de trilhas no 
território. Todavia, em uma perspectiva mais expandida, incluem-se aí a formação de artesões, cozinheiros, empreendedores e todos os tipos de profissionais envolvidos na geração do desenvolvimento local.

Ainda assim, considerando o estágio embrionário do debate geoeducacional dentro dos geoparques, a maior parte das iniciativas ainda está concentrada na construção de instrumentos didáticos voltados especialmente à compreensão das Ciências da Terra (figura 4)
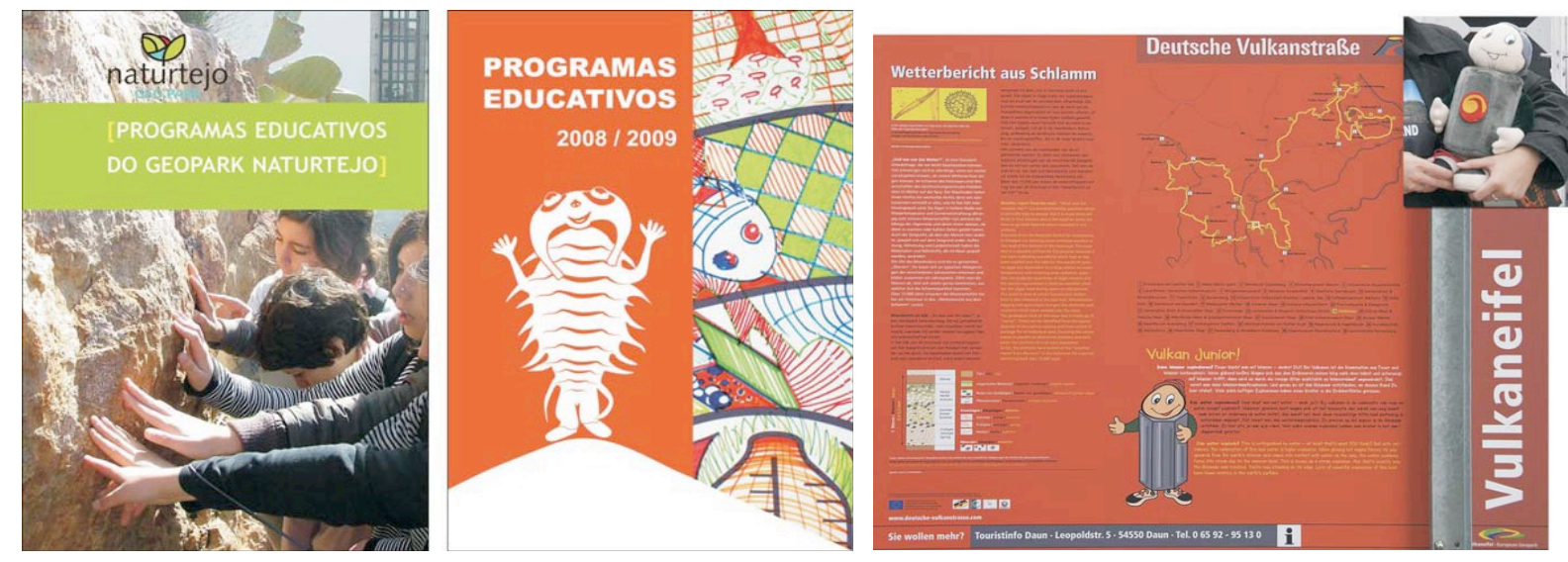

Figura 4: Programas educativos dos Geoparques Naturtejo e Arouca (Portugal) e do Geoparque

Vulkaneifel (Alemanha). Estes materiais não apenas subsidiam os processos educativos nos respectivos Geoparques, como a sua comercialização corresponde também a uma forma de renda para estes territórios.

Fonte: Brilha (2009).

Assim, a geoeducação, quando associada a temática do geopatrimônio, serve como um dos principais incentivadores de um ambiente propicio a abordagem de questões geoconservacionistas, já que oferece suporte didático ao aprendizado e à realização de experiências interpretativas envolvendo as mais diferentes temáticas que dizem respeito ao território visitado/vivido. Mais do que isso, a geoeducação desafia os especialistas para a construção de recursos interpretativos inovadores (MartínezFrías et al., 2016), capazes não apenas de traduzir um conhecimento das ciências da Terra para a linguagem educativa mas, acima de tudo, despertar o interesse, estimular a inteligência sinestésica no contato com a natureza, ampliar a colaboração e oferecer uma alternativa de entretenimento cultural aos visitantes e aos moradores.

Para que esta geoeducação possa efetivamente envolver o território e a sociedade que nele habita e visita, é fundamental que se possa iniciar por estratégias direcionadas à educação formal, oferecendo uma formação complementar especifica aos professores, associada a materiais e dinâmicas atraentes para os educandos, que colabore para o estabelecimento de um currículo que valorize os aspectos patrimoniais do local. Estes materiais podem ser entendidos como ferramentas lúdicas, como jogos, histórias, teatros, entre outros; além disso existem outros materiais didáticos que auxiliam na dinâmica em sala de aula com amplo potencial interdisciplinar, facilitando a compressão do aluno para diferentes temáticas, como 
jogos, maquetes, mapas, aplicativos, etc. O presente trabalho tem como objetivo abordar os materiais que estão sendo desenvolvidos dentro da proposta do geoparque quarta colônia, a partir do projeto de extensão "Geoparque vai à Escola", executado pelo Grupo de Pesquisa em Patrimônio Natural, Geoconservação e Gestão da Água (PANGEA) da UFSM.

O projeto Geoparque Quarta Colônia está localizado na região central do Rio Grande do Sul, formado por nove municípios com grande potencial patrimonial geológico, ecológico e histórico-cultural (Figura 5). De acordo com Ziemann (2015), a região possui feições variadas, tais como afloramentos fóssilíferos, miradouros, cascatas, grutas e escarpas alagadas, totalizando vinte quatro geossítios.
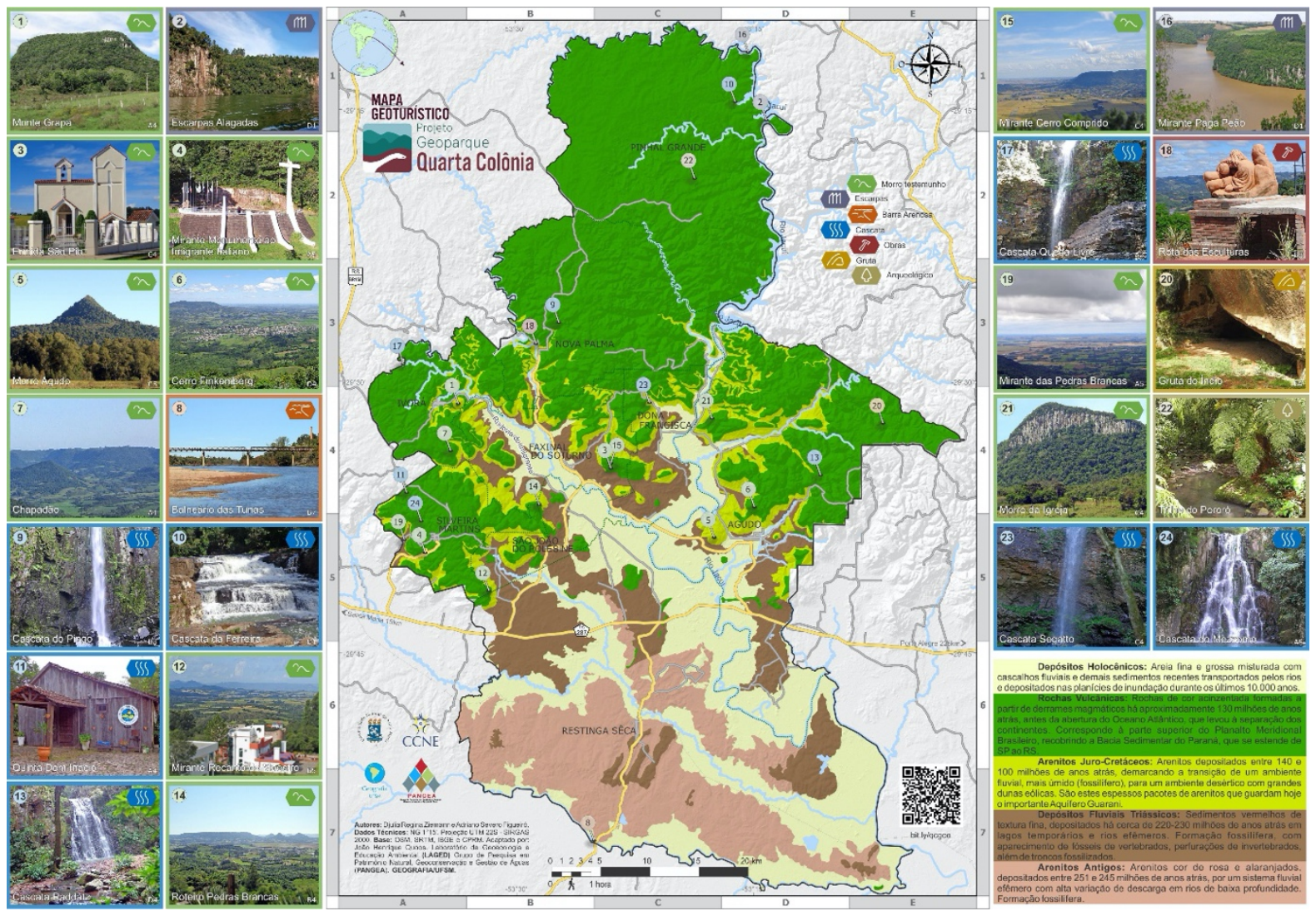

Figura 5: Mapa geoturístico do Geoparque Quarta Colônia - RS.

Fonte: PANGEA.

Do ponto de vista geológico, esta área compreende a parte mais meridional da Bacia do Paraná, que evoluiu no Rio Grande do Sul desde o Período Permiano ao Cretáceo. As rochas, nas porções mais baixas do território (área da Depressão Central), são arenitos, siltitos e argilitos fossilíferos, representativos do Período Triássico (Formações Santa Maria e Caturrita); estratigraficamente acima, estão os arenitos eólicos (Formação Botucatu) e, compondo a porção mais alta e recobrindo todo o Planalto, os basaltos da Formação Serra Geral, registro de um dos mais volumosos eventos ígneos da história do planeta (Zerfass, 2007). 
Em se tratando da história da vida na Terra, a região guarda fósseis triássicos de importância internacional, representados por belos exemplares de vertebrados, que compreendem desde pequenos esfenodontes e procolofonídeos, dinossauros basais, delicados registros de flores, troncos e ramos de coníferas, além de rastros de vários icnogêneros (Langer et al., 2007).

Um primeiro inventário do território produzido por Godoy et al (2012) identificou vinte geossítios com alto valor patrimonial na Quarta Colônia, demandando a construção de estratégias educativas para a sua interpretação. Trabalho posterior de Ziemann (2015), ampliou este inventário para 43 geossítios. Uma avaliação do potencial geoturístico destes geossítios, realizada por Ziemann e Figueiró (2017), demonstrou que apenas 24 geossítios apresentam condições adequadas para o desenvolvimento de processos interpretativos aos visitantes, sendo este o foco principal de produção de materiais pedagógicos atualmente em curso no projeto.

\section{Materiais desenvolvidos}

Os materiais aqui apresentados foram ou estão sendo elaborados no Laboratório de Geoecologia e Educação Ambiental na Universidade Federal de Santa Maria, para auxiliar na divulgação dos geossítios como ferramenta educativa e facilitar a comunicação entre a proposta do geoparque Quarta Colônia com a comunidade escolar.

Considerando que o projeto "Geoparque Vai à Escola" representa um projeto de extensão permanente de assessoramento didático à gestão territorial do Geoparque, várias outras ferramentas foram, estão sendo ou serão produzidas para alimentar a construção de um programa educativo do GQC. Preliminarmente, o que será divulgado aqui refere-se às ferramentas que estão sendo produzidas no momento, mais diretamente ligadas à educação formal nas escolas do território, que consistem de uma coleção de cadernos didáticos, de um jogo de RPG, de uma maquete de mesa e de maquetes de mão, utilizadas para aulas de campo.

\subsection{Coleção de Cadernos Didáticos}

O caderno didático surge da necessidade de divulgação dos geossítios da proposta de Geoparque Quarta Colônia para o público escolar, localizando cada geossítio com sua descrição, em conjunto com algumas curiosidades dos pontos abordados, traduzindo de uma linguagem técnica e científica para uma forma simples e de fácil compreensão para o público alvo.

A proposta é que esta coleção seja composta de três volumes, abordando três diferentes momentos da escala de tempo do território: no volume 1 trata-se do Geoparque no tempo profundo, traduzindo aos leitores o processo de formação e transformação das paisagens da Quarta Colônia desde o Mesozóico até o Pleistoceno, compreendendo as mudanças climáticas, a dinâmica geológicogeomorfológica e a evolução biótica que as acompanhou (Figura 6). No volume 2, trata-se do Geoparque no tempo geológico recente, apresentando aos leitores as transformações da natureza que se processaram a partir do holoceno, 
desencadeadas pelas condições climáticas úmidas do período interglacial que estamos vivendo, com destaque para a expansão da Mata Atlântica que recobre a maior parte do território do Geoparque. Já no volume 3, trata-se do Geoparque no tempo histórico, apresentando as transformações da paisagem que se processaram a partir da ocupação humana, desde os primeiros indígenas, até a chegada dos imigrantes e a formação do território atual.

Na condição de um material paradidático, esta coleção foi pensada não apenas como um livro de consulta para os estudantes, mas como uma ferramenta interativa, onde estão presentes atividades lúdicas (como imagens para pintar, cruzadinhas, sete erros, caça palavras, jogo das sombras, etc.), conceitos, informações e glossários.
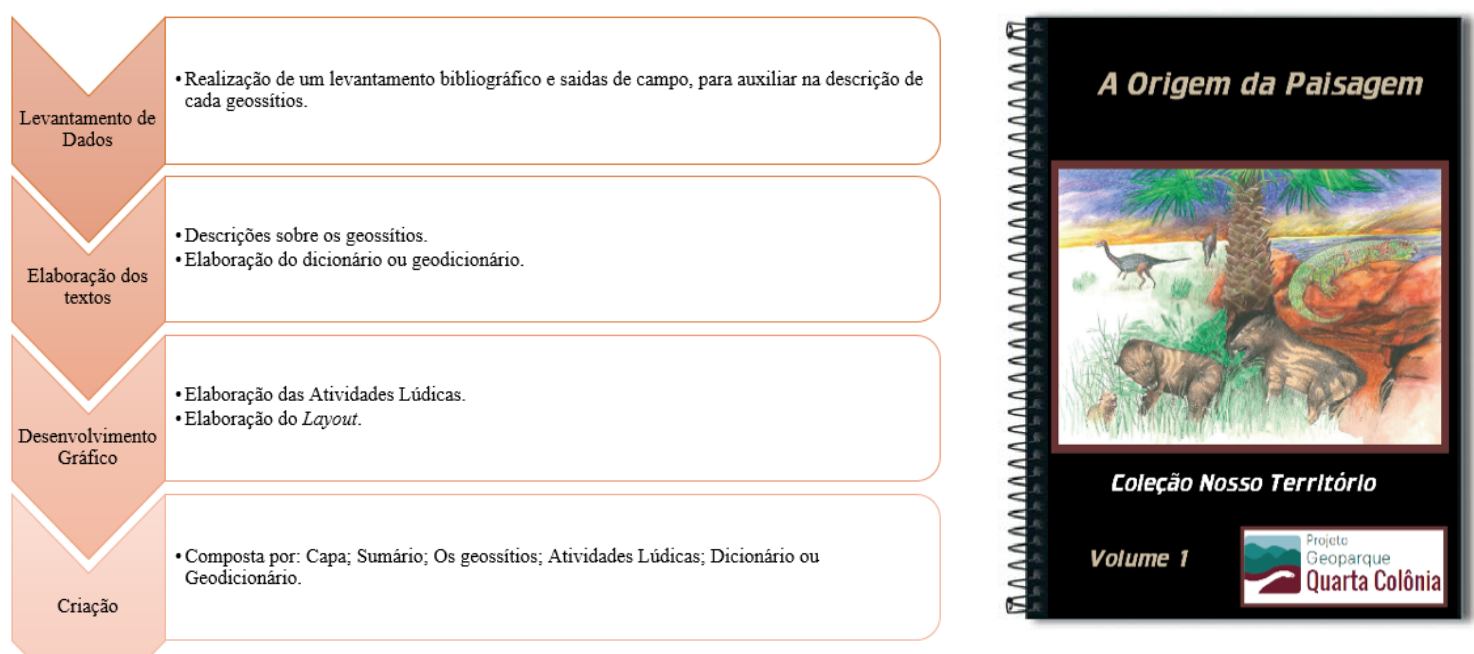

Figura 6: Sequência de etapas para a criação dos Cadernos Didáticos e capa do Volume 1.

Fonte: Elaborado pelos autores.

\subsection{Role-Playing Game "Q.C.RPG"}

Para permitir uma interação mais dinâmica entre os educandos e os potenciais geoturísticos da Quarta Colônia, foi desenvolvido um jogo de interpretação de papeis (RPG), que consiste em "(...) atividades cooperativas nas quais um grupo de jogadores, geralmente em um número de quatro até dez simultaneamente, criam uma história oral, escrita ou animada e não-linear, utilizando-se como plano de jogo a imaginação, esboços, gestos, falas, textos e imagens" (Schmit, 2008, p. 23). Dentro do jogo os geossítios escolhidos foram explorados nas suas características estéticas, históricas e culturais, permitindo abordar e discutir os temas pertinentes ao projeto do geoparque. A escolha do formato de RPG se dá pela possibilidade de transformar o jogador em um agente ativo da narrativa, tomando para si a problemática a ser resolvida.

A narrativa central do jogo se desenrola em torno da história de um assalto realizado no Centro de Apoio à Pesquisa Paleontológica (CAPPA), onde o fóssil de um dos 
últimos dinossauros identificados (Macrocollum Itaquii) foi roubado e seus fragmentos distribuídos em diferentes geossítios do território. O desafio colocado aos participantes refere-se à necessidade de recuperar tais fragmentos, superando desafios colocados pelo mestre do jogo, retornando ao CAPPA ao final para remontar o fóssil (Figura 7). Para garantir a fluidez do jogo, foram construídas Cartas de Campo (com a função de inserir e localizar o jogador dentro da narrativa), Cartas de Nonplayer Character -NPC (representam os atores passivos da história, servindo como suporte à narrativa) e as Cartas de Jogador (onde se registram os atributos e a habilidade única de cada classe de personagem envolvido no jogo - geógrafo, político ou turista).

$\mathrm{Na}$ construção, foram elaboradas ferramentas auxiliares baseadas em outros formatos para facilitar o entendimento da metodologia para o público alvo.

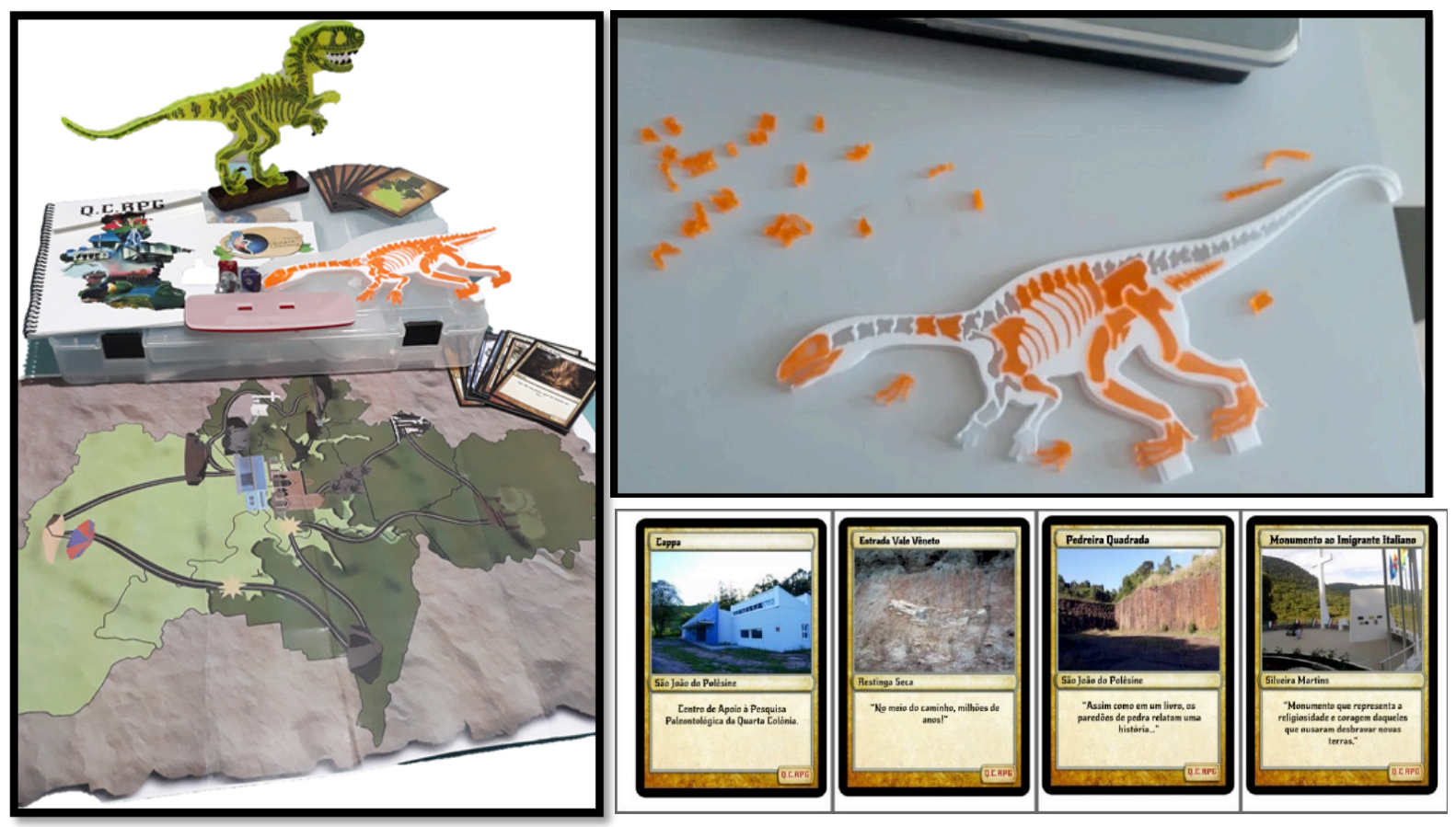

Figura 7: Visão geral do RPG elaborado (esq.) e, no detalhe, exemplo das cartas de campo e do fóssil do dinossauro (Macrocollum Itaquii) produzido em resina (dir.).

Fonte: Motta (2019).

\subsection{Maquete de mesa do Geoparque}

As maquetes são representações em escala reduzida da realidade, possibilitando ao observador compreender a integralidade do território, na sua estrutura e conexões; isso permite fazer análises que passam do plano abstrato para o concreto, uma vez que na maquete a espacialidade do território se torna visível. Nas palavras de Pitano e Roqué (2015), a maquete “(...) propicia a valorização local e a solução de problemas, desde o espaço físico ao social, ligando o ensino da disciplina ao cotidiano do aluno, pois possibilita mostrar a organização e a ocupação do espaço, além da interação com o meio representado na maquete" (p. 276). 
A maquete foi criada a partir do mosaico de doze cartas topográficas da Quarta Colônia, disponibilizadas pelo Ministério do Exército na escala de 1:50.000. Como instrumento pedagógico de compreensão do território, a maquete foi pensada para fazer parte do futuro centro interpretativo do Geoparque Quarta Colônia, integrado ao Centro de Apoio à Pesquisa Paleontológica (CAPPA) da UFSM, localizado no município de São João do Polêsine. Dada a necessidade de poder ser observada por um número mais amplo de visitantes ao mesmo tempo, a construção da maquete, realizada com isopor e massa corrida apoiada em suporte de madeira (Figura 8), foi projetada para um tamanho de aproximadamente $9 \mathrm{~m}^{2}(3,56 \mathrm{mX2,52m)}$, com um exagero vertical de 5 vezes.

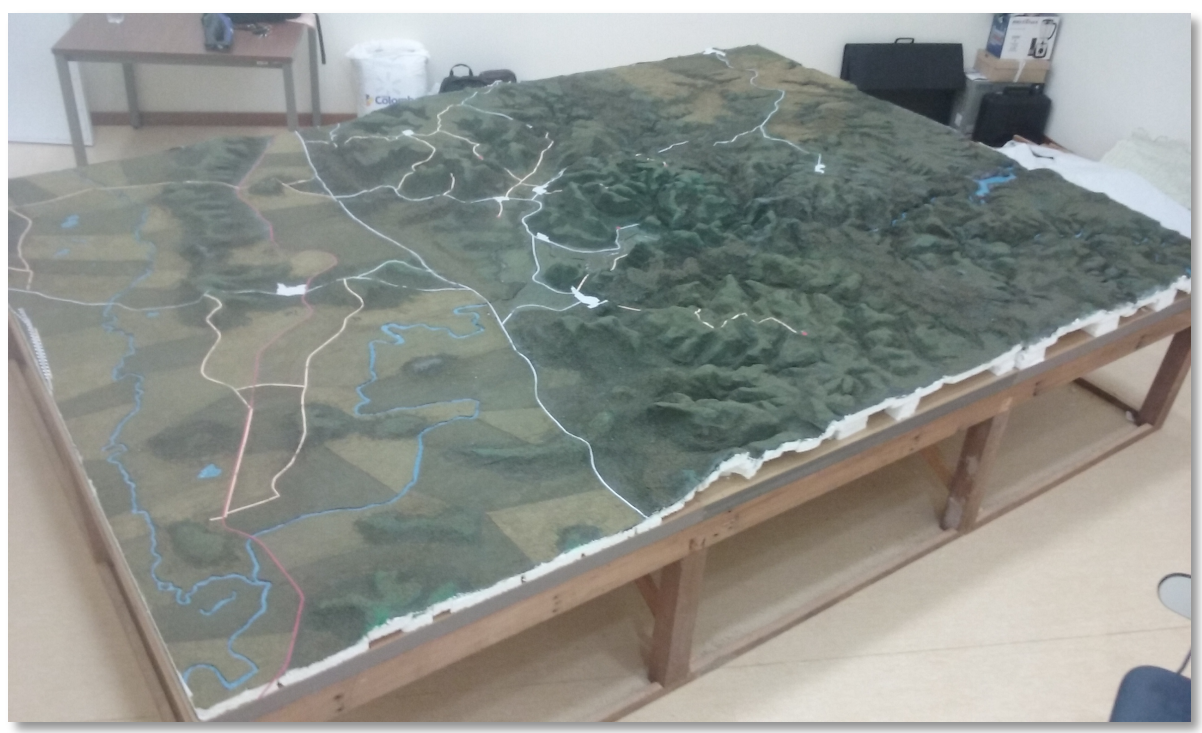

Figura 8: Visão geral maquete de mesa ainda em processo de construção. Fonte: Acervo de imagens dos autores.

Sobre esta maquete, estarão representados os geossítios de potencial geoturístico do Geoparque selecionados por Ziemann e Figueiró (2017), além da localização dos principais patrimônios culturais inventariados no território por Sechin (2019), permitindo aos visitantes uma visão integral dos nove municípios que compõe o Geoparque, além da observação dos dois grandes conjuntos topográficos presentes no território: a escarpa meridional do Planalto Brasileiro ao norte, e a Depressão Central do RS ao sul da área.

\subsection{Maquete de mão do Geoparque}

Ao mesmo tempo em que se estava construindo uma maquete de mesa para servir como instrumento interpretativo aos visitantes do futuro centro de interpretação do Geoparque, se buscou desenvolver um modelo mais reduzido para que se possa utilizar em campo, seja com alunos das escolas do território ou mesmo com visitantes nos geossítios. Cabe ressaltar que o formato tridimensional e a possibilidade de ser levado em passeios e deslocamentos de campo permitem ao público leigo uma rápida 
compreensão das formas do relevo no local visitado, materializando a experiência da percepção da paisagem em um objeto tátil.

A opção construtiva, em função da rapidez e facilidade de produção, recaiu sobre a impressão em 3D. A impressão 3D, ou Fused Deposition Modeling (FDM - Modelagem por Fusão e Depósito) funciona através da adição de camadas sobrepostas de um filete plástico que é aquecido e injetado em uma base, que se movimenta em dois eixos e cria as camadas a partir de um modelo tridimensional previamente inserido no computador (Figura 9). O modelo produzido foi impresso e posteriormente pintado a mão em um tamanho de $11 \mathrm{~cm} \times 14 \mathrm{~cm}$; todavia, em função do custo de impressão, a reprodução de um número maior de exemplares demonstrou-se inviável neste momento. Assim, para viabilizar esta reprodução, se está trabalhando experimentalmente com a possibilidade de utilizar o protótipo impresso como modelo positivo para gerar um negativo em silicone e, a partir disso, reproduzir cópias em resina, a um custo incomparavelmente mais baixo do que a impressão em 3D. Dessa forma, além de servir como instrumento para a educação, a reprodução da maquete pode servir como um geoproduto, pois sua forma está ligada à geodiversidade do local, agregando um valor ainda maior à experiência do geoturismo por meio de um artesanato inovador.

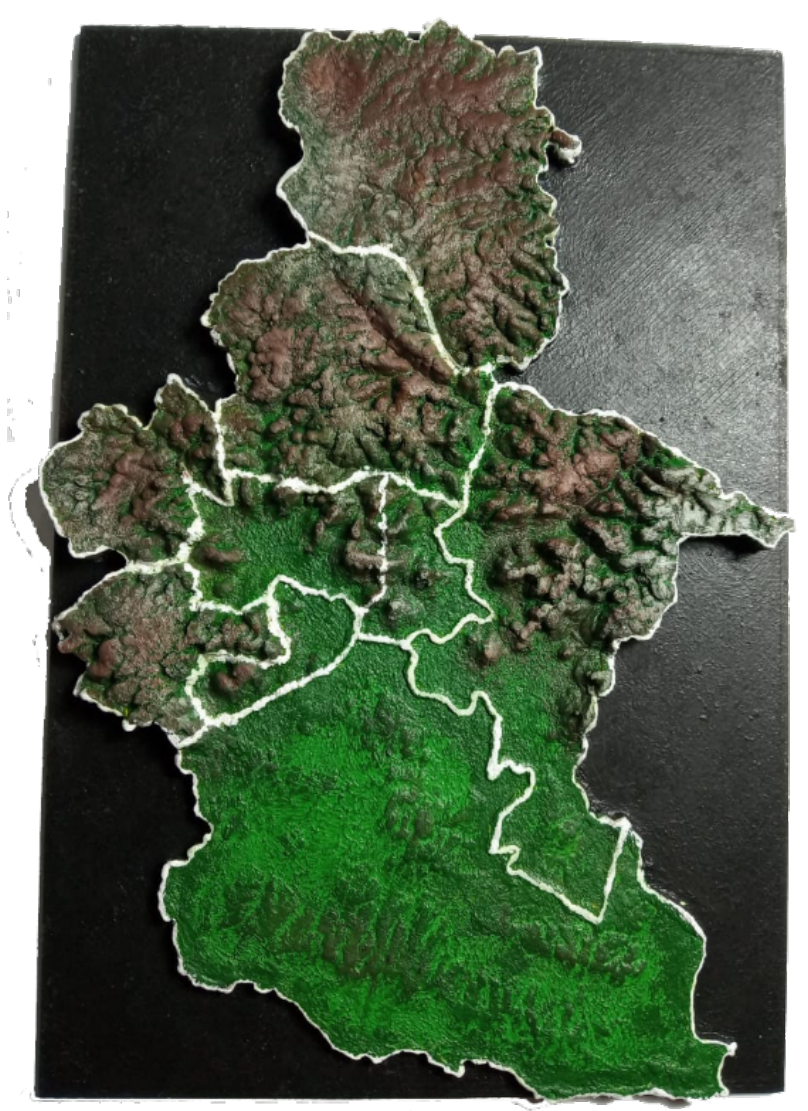

Figura 9: Maquete de mão produzida por impressão em 3D. Fonte: Acervo de imagens dos autores 
Alternativamente, se buscará também produzir um protótipo em usinagem por Controle Numérico Computadorizado (CNC), que é uma tecnologia de fabricação subtrativa simples. Orientada por comandos recebidos por um computador, essa técnica utiliza ferramentas rotativas afiadas e cortantes para extrair material de um objeto sólido e assim obter uma forma final tridimensional. O CNC oferece alta precisão, qualidade de acabamento, velocidade e variedade de materiais que vão de polímeros e metais até madeira no processo de usinagem.

\section{Considerações finais}

$\mathrm{Na}$ região da proposta do Geoparque Quarta Colônia já existem estratégias de divulgação para a comunidade, como o Paleodia, que ocorre no mês de outubro para difundir o conhecimento geocientifico para a comunidade. Adicionalmente, os materiais educativos em desenvolvimento contribuirão para fomentar a discussão da proposta em sala de aula, se tornando, no olhar dos autores, importantes instrumentos didáticos voltados à proposta do Geoparque Quarta Colônia.

Todos os instrumentos aqui apresentados têm o intuito de aproximar os educandos e os visitantes da realidade do território do Geoparque por meio de uma aprendizagem ativa, que corresponde a uma maneira de se aproximar e estar ativamente envolvido na aprendizagem dos indivíduos. O aprendizado ativo cultiva diferentes habilidades dos educandos, incluindo cognição, ética, competência social, cultura e conhecimento (Takayuki, 2016).

Por fim, é preciso ressaltar sempre que os Geoparques são feitos por pessoas e para pessoas, sendo que o aspecto educativo representa uma mediação fundamental para despertar o interesse da sociedade para conhecer e proteger seu patrimônio, sem o qual, qualquer modelo de desenvolvimento territorial está fadado a fracassar em médio ou longo prazo, por desconsiderar os limites e as potencialidades de um sistema paisagístico sempre complexo e com graus variados de resiliência.

\section{Bibliografia}

Azman, N., Halim, S. A., Liu, O. P., Komoo, I. (2011). The Langkawi Global Geopark: local community's perspectives on public education. International Journal of Heritage Studies, 17 (3), 261-279. https://doi.org/10.1080/13527258.2011.557863

Brilha, J. B. R. (2009). A Importância dos Geoparques no Ensino e Divulgação das Geociências. Revista do Instituto de Geociências - USP, 5, 27-33. http://dx.doi.org/10.11606/issn.2316-9087.v5i0p27-33

Borba, A. W. (2011). Geodiversidade e geopatrimônio como bases para estratégias de geoconservação: conceitos, abordagens, métodos de avaliação e aplicabilidade no contexto do Estado do Rio Grande do Sul. Pesquisas em Geociências, 38(1), 3-13. https://doi.org/10.22456/1807-9806.23832

Edelson, D.C. (2012). Geo-literacy. Disponível em 23/10/2019, em: http://education.nationalgeographic.com/education/geoliteracy/?ar a=1\&force AR=True 
Farsani, N. T., Coelho, C. O. A., Costa, C. M. M., Amrikazemi, A. (2014). Geo-knowledge Management and Geoconservation via Geoparks and Geotourism. Geoheritage, 6(3), 185192. https://doi.org/10.1007/s12371-014-0099-7

Godoy, M. M., Binotto, R. B., Silva, R. C. da, Zerfass, H. (2012). Geoparques/propostas: Quarta Colônia (RS). In: Schobbenhaus, C., Silva, C. R. da (Org.). Geoparques do Brasil: propostas. (pp. 417-456). Rio de Janeiro: CPRM.

Langer, M. C., Ribeiro, A. M., Schultz, C. L., Ferigolo, J. (2007). The continental tetrapodbearing Triassic of south Brazil. New Mexico Museum of Natural History and Science Bulletin, 41, 201-218.

Martínez-frías, J., Mateo Mederos, M. E., Lunar, R. (2016). Los geoparques como áreas de investigación, geoeducación y geoética en geociências planetarias: el geoparque de Lanzarote y Archipiélago Chinijo. In: IX Congreso Geológico de España, Huelva.

Motta, V. (2019). O uso do RPG como instrumento didático no projeto do Geoparque Quarta Colônia/RS. Dissertação de Graduação em Geografia Licenciatura, Universidade Federal de Santa Maria, Santa Maria/RS.

NGS - NATIONAL GEOGRAPHIC SOCIETY. (sd) Geo-education: essential preparation for an interconnected world. Disponível em 23/10/2019, em: https://www.nationalgeographic.org/education/geo-education-essential-preparationinterconnected-world/

Pereira, R. G. F. de A. (2010). Geoconservação e desenvolvimento sustentável na Chapada Diamantina (Bahia - Brasil). Tese Doutoramento em Ciências. Braga: Univ. Minho.

Pitano, S. C., Roqué, B. B. (2015). O uso de maquetes no processo de ensino-aprendizagem segundo licenciandos em Geografia. Educação Unisinos, 19(2), 273-282. https://doi.org/10.4013/edu.2015.192.11

Schmit, W. (2008). RPG e educação: Alguns apontamentos teóricos. Dissertação de Mestrado em Educação, Universidade Estadual de Londrina.

Sechin, D. N. (2019). Estratégias interpretativas integradas para o patrimônio cultural, natural e paleontológico da Quarta Colônia-RS. Texto inédito.

Soares, D. B., Santos, V. M. N. (2017). Educação, Ambiente e Aprendizagem Social na Formação de Professores para Geoconservação. Terræ, 14(1-2), 41-53. http://dx.doi.org/10.24109/2176-6681.rbep.98i249.2758

Takayuki, A. (2016). Overview: The Educational Capabilities of Geoparks: From Education to Learning. Journal of Geography, 125(6), https://doi.org/10.5026/jgeography.125.775

Van Loon, A. J. (2008). Geological education of the future. Earth-Science Reviews, 86(1-4), 247-254. https://doi.org/10.1016/j.earscirev.2007.08.005

Zerfass, H. (2007). Geologia da Folha de Agudo, SH.22-V-C-V, escala 1:100.000. Serviço Geológico do Brasil-CPRM, CD-ROM.

Ziemann, D. R. (2015). Levantamento preliminar do potencial geoturístico no território do projeto geoparque Quarta Colônia, RS. In: XI Encontro Nacional da ANPEGE. Disponível em

23/10/2019,

em: 
https://www.researchgate.net/publication/282976362 levantamento preliminar do poten cial geoturistico no territorio do projeto geoparque quarta colonia rs

Ziemann, D. R., Figueiró, A. S. (2017). Avaliação do Potencial Geoturístico no Território da Proposta Geoparque Quarta Colônia. Revista do Departamento de Geografia, 34, 137-149. https://doi.org/10.11606/rdg.v34i0.135156

Artigo recebido em/ Received on: 27/11/2019

Artigo aceite para publicação em/ Accepted for publication on: 29/12/2019 